\title{
Variability of air temperature over a debris-covered glacier in the Nepalese Himalaya
}

\author{
Jakob F. STEINER, ${ }^{1}$ Francesca PELLICCIOTTI ${ }^{1,2}$ \\ ${ }^{1}$ Institute for Environmental Engineering, Institute of Technology (ETH), Zürich, Switzerland \\ ${ }^{2}$ Department of Geography, University of Northumbria, Newcastle, UK \\ Correspondence: Jakob F. Steiner <stjakob@ethz.ch>
}

\begin{abstract}
Estimates of melt from debris-covered glaciers require distributed estimates of meteorological variables and air temperature in particular. Meteorological data are scarce for this environment, and spatial variability of temperature over debris is poorly understood. Based on multiple measurements of air and surface temperature from three ablation seasons (2012-14) we investigate the variability of temperature over Lirung Glacier, Nepal, in order to reveal how air temperature is affected by the debris cover and improve ways to extrapolate it. We investigate how much on-glacier temperature deviates from that predicted from a valley lapse rate (LR), analyse on-glacier LRs and test regression models of air temperature and surface temperature. Air temperature over the debris-covered glacier tongue is much higher than what a valley LR would prescribe, so an extrapolation from offglacier stations is not applicable. An on-glacier LR is clearly defined at night, with strong correlation, but not during the day, when the warming debris disrupts the elevation control. An alternative to derive daytime air temperature is to use a relationship between air and surface temperature, as previously suggested. We find strong variability during daytime that should be accounted for if these regressions are used for temperature extrapolation.
\end{abstract}

KEYWORDS: debris-covered glaciers, energy balance, glacier meteorology, mountain glaciers

\section{INTRODUCTION}

Air temperature is one of the main controls of the energy balance of glaciers, and the main input variable to melt and mass-balance models. Little is known, however, about its variability over melting glaciers, and most modelling studies assume that it varies linearly with elevation, a concept reproduced by so-called lapse rates (LRs) or temperature gradients. This assumption, which is valid in the case of free atmospheric conditions, does not take into account the effect of terrain (Minder and others, 2010), and the presence of glaciers in particular (Greuell and Boehm, 1998; Petersen and Pellicciotti, 2011; Ayala and others, 2015). A number of recent studies have shown that temperature variability over bare-ice glaciers is complex and not reproduced by constant LRs (Shea and Moore, 2010; Petersen and Pellicciotti, 2011; Petersen and others, 2013).

Even more limited is our knowledge of air temperature over debris-covered glaciers. Debris-covered glaciers, mantled in a layer of debris varying from a few centimetres to several metres of material of different sizes and composition, are common features in many mountain ranges worldwide, especially in the Hindu Kush-KarakoramHimalaya $(\mathrm{HKH})$ region (Scherler and others, 2011; Benn and others, 2012; Bolch and others, 2012). Because of the lack of a $0^{\circ} \mathrm{C}$ surface and the movement of air being dominated by surface convection from debris-cover heating under good weather conditions, katabatic flows (i.e. the down-glacier gravitational movement of cooled and thus denser air parcels) generally do not develop over such glaciers (Shaw and others, 2016).

However, it is not clear whether the lack of this phenomenon typical of debris-free glaciers means that elevation is restored as a main control over air temperature, and very few studies have looked at air temperature variability over debris-covered glaciers.

Brock and others (2010) analysed temperature data from two automatic weather stations (AWSs) over the debriscovered tongue of Miage glacier, Italian Alps, and found LRs between $-0.0080^{\circ} \mathrm{C} \mathrm{m}^{-1}$ and $-0.0067^{\circ} \mathrm{C} \mathrm{m}^{-1}$ over different seasons, and a pronounced diurnal cycle. These values are more negative than the environmental lapse rate (ELR) of $-0.0065^{\circ} \mathrm{C} \mathrm{m}^{-1}$ and considerably steeper than typical debrisfree glacier LRs (e.g. $-0.0032^{\circ} \mathrm{C} \mathrm{m}^{-1}$ for Haut Glacier d'Arolla, Swiss Alps (Petersen and others, 2013)). Fujita and Sakai (2000) measured air and surface temperature on the debris-covered tongue of Lirung Glacier and at an offglacier site, and calculated LRs between the two sites over the period May to October 1996, differentiating between seasons. A steep LR $\left(-0.0075^{\circ} \mathrm{C} \mathrm{m}^{-1}\right)$ was also calculated by Mihalcea and others (2006) for Baltoro Glacier, Pakistan; however, the lower AWS was located not on the glacier but on the moraine ridge, so the representativeness of the calculated LR may be questionable.

Lapse rates calculated from only two stations suffer from lacking any indication of the strength of the temperatureelevation relationship. The correlation coefficients of a linear regression fitted to more than two measurements can enable this; however, it requires a multitude of sensors, and no previous field experiment has provided such a set-up over debris-covered glaciers.

Foster and others (2012) suggested that over debriscovered glaciers surface temperature is a stronger control on air temperature variability than elevation, and used a linear relationship derived from air and surface temperature records at one AWS to derive a distributed field of $2 \mathrm{~m}$ air temperature over Miage glacier. While it is evident that thick 


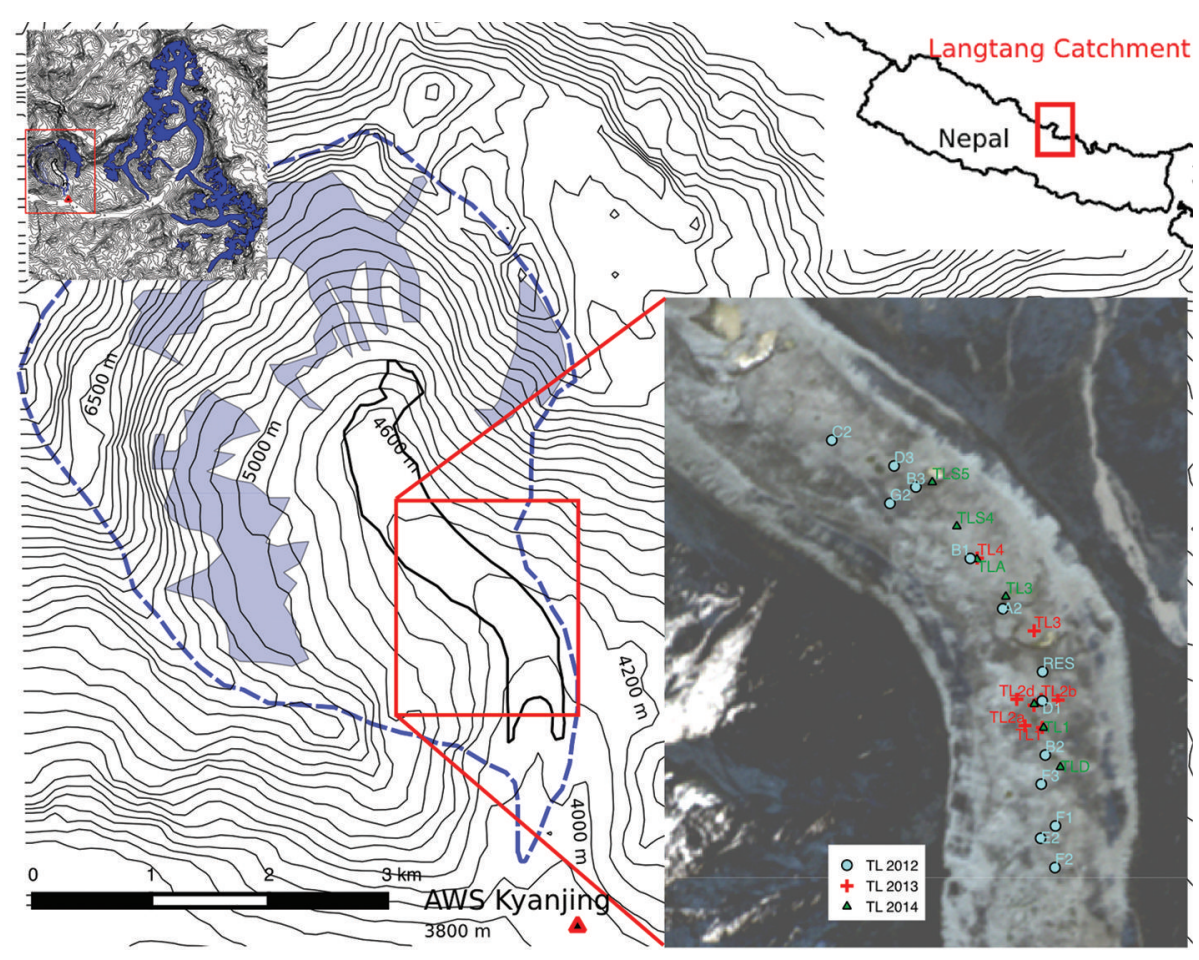

Fig. 1. Map of Lirung Glacier in the Langtang catchment (shown in top left inset), located in the Nepalese Himalaya (top right inset). The black border indicates the debris-covered area, the blue area the debris-free glacier area, and the dashed blue line the catchment borders. The position of Kyanjing AWS is marked in the main map, and the locations of the temperature sensors (T-Loggers) are provided in the main inset, showing the lower section of Lirung tongue (background image is a Rapid Eye image of 25 March 2010).

debris can heat up considerably during the day, thus affecting the overlying air, it is not clear that the relationship identified is significant enough, constant in time or uniform in space.

Knowledge of spatial fields of air temperature seems important for forcing distributed models of melt under debris, and methods to calculate these fields are still lacking. The few existing distributed models of debris ablation have been forced with air temperature extrapolated with constant LRs (e.g. Zhang and others, 2011; Reid and others, 2012; Fujita and Sakai, 2014; Fyffe and others, 2014), but that has not been supported by evidence and might introduce uncertainties in modelled ablation (Reid and others, 2012).

In this paper we use a new dataset of $2 \mathrm{~m}$ air temperature records at a network of locations over the debris-covered tongue of Lirung Glacier, Nepalese Himalaya, collected over three seasons (2012-14), to investigate air temperature variability in space and time. The aims of the paper are: (1) to use the data collected to test whether elevation is a main control on air temperature over a debris-covered glacier; (2) to identify possible alternative controls related to debris characteristics; and (3) to test, in both space and time, the robustness of the relationship identified by Foster and others (2012).

\section{STUDY SITE}

Lirung Glacier $\left(28^{\circ} 13^{\prime} 57^{\prime \prime} \mathrm{N}, 85^{\circ} 33^{\prime} 43^{\prime \prime} \mathrm{E}\right)$, is located in the Upper Langtang catchment (Fig. 1), which covers an area of $350 \mathrm{~km}^{2}, \sim 30 \%$ of which is glacierized (Shiraiwa and Yamada, 1991; Ragettli and others, 2015). Debris-covered glaciers are among the largest in the catchment, and represent $\sim 25 \%$ of the total glacierized area (Pellicciotti and others, 2015; Ragettli and others, 2015). Of these glaciers, Lirung Glacier has the greatest elevation range (4050-7132 m a.s.I.), with debris cover extending from 4050 to $4650 \mathrm{~m}$ a.s.l. Its total area is $>6 \mathrm{~km}^{2}$, with $>20 \%$ covered in debris (Shiraiwa and Yamada, 1991). The debris-covered tongue has a length of $3.5 \mathrm{~km}$ and an average width of $500 \mathrm{~m}$ (Immerzeel and others, 2014a). The ablation area is currently detached from the accumulation zone (e.g. Steiner and others, 2015).

The catchment climate is dominated by the Indian monsoon, which lasts from June to September. Most of the annual precipitation falls during this period, which is characterized by persistent overcast conditions (Immerzeel and others, 2014a,b; Ragettli and others, 2015). The premonsoon season is warmer on average, while the postmonsoon season is considerably colder. The dates defining the seasons (Table 1) are based on analysis of temperature and precipitation time series, corresponding to Steiner and others (2015).

The debris-covered tongue of Lirung Glacier has a rough topography, with a succession of depressions and local debris mounds, ridges and troughs, and elevation differences of up to $100 \mathrm{~m}$ within a lateral distance of 200-300 m. Numerous supraglacial ponds and ice cliffs exist, and cliffs range in height from 5 to $50 \mathrm{~m}$.

\section{MEASUREMENT SET-UP AND METHODS}

\section{Measurement set-up}

Between 2012 and 2014 two field campaigns were carried out annually on the glacier, in May (pre-monsoon) and from mid-October to mid-November (post-monsoon). Sensors were installed during the first visit, left in place for the 


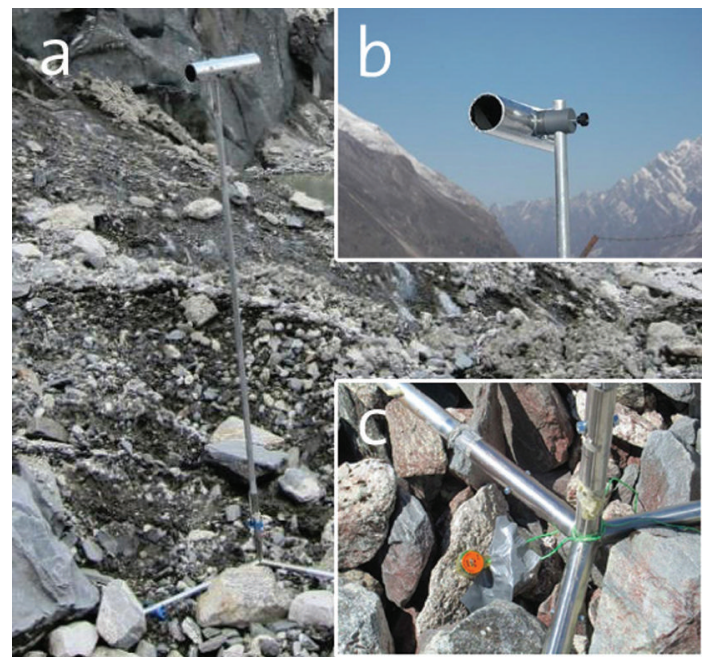

Fig. 2. T-Logger structure (a), consisting of air temperature measurements $2 \mathrm{~m}$ above ground, where the sensor is placed in a cylinder shielded from solar radiation with aluminium foil and aligned in the direction of the valley (b), and a surface sensor taped to a rock and roped to the base structure (shown here without shielding; c).

duration of the monsoon and data were read out during the second visit after the monsoon. The measurement periods are listed in Table 1.

Air and surface temperatures were measured using a network of T-Loggers (Fig. 1). The sensors were Onset TidBits (UTBI-001). The air temperature sensors were placed at a height of $2 \mathrm{~m}$ (Fig. 2a); at most locations, surface temperature was also recorded. The air temperature sensors were placed in a cylinder covered with aluminium foil as a shield against radiation (Fig. 2b; Petersen and Pellicciotti (2011) provide details of the sensor set-up). Sensors at the surface were covered in foil in 2013 and 2014 but not in 2012 (Fig. 2c). The locations of the T-Loggers were measured with handheld GPS in 2012 and during a more accurate differential GPS survey in 2013 and 2014. Temperature data from a Rotronic SC2 sensor at an offglacier AWS in Kyanjing were available throughout the investigation (Fig. 1).

In 2012, 13 T-Loggers were distributed over a large part of the tongue to cover a relatively large elevation range of $203 \mathrm{~m}$ (Fig. 3; long tongues of debris-covered glaciers tend to be relatively flat). They were generally located on top of debris mounds. In 2013, eight T-Loggers were located closer together around a glacier AWS, only $48 \mathrm{~m}$ apart in elevation. They were densely distributed over a small plot at locations with different characteristics, some of them on slopes or mounds, others in depressions. In 2014, some of the locations around the AWS were re-instrumented, but

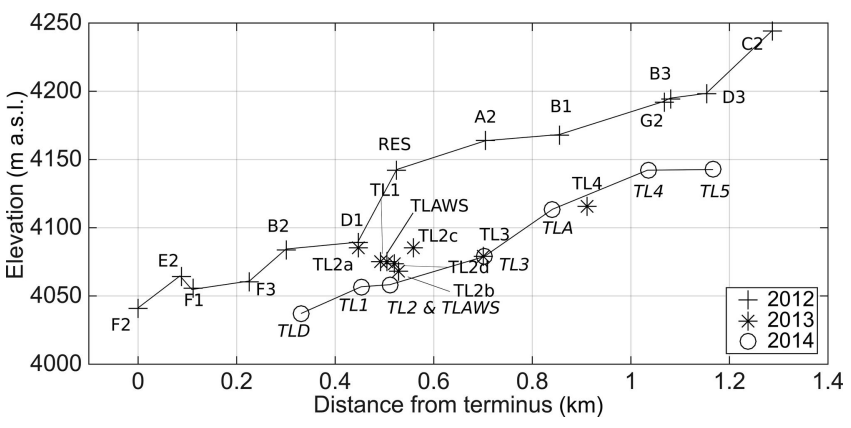

Fig. 3. Elevation of the T-Loggers in 2012, 2013 and 2014. The zero mark on the $x$-axis represents the lowest point of the debris-covered tongue. Labels for 2014 are in italics. Lines for 2012 and 2014 indicate the level of the surface where the T-Loggers were placed but do not indicate the actual profile of the surface, as the T-Loggers were not all aligned along the same longitudinal profile.

additional T-Loggers were located up- and down-glacier, both on slopes between mounds and depressions and in large depressions. A total of seven T-Loggers were deployed in this year. These set-ups enabled the investigation of LRs over the extent of the lower tongue in 2012 and of smallscale effects over the rough topography in 2013. In 2014 the set-up was between the former and the latter, with sensors distributed over the length of the glacier tongue, over an elevation range of $106 \mathrm{~m}$, but with more placed in depressions than on debris mounds.

We also use a high-resolution digital elevation model (DEM) $(20 \mathrm{~cm})$ of the glacier surface derived from a survey with an unmanned aerial vehicle (UAV) in May 2013 (Immerzeel and others, 2014), which was employed to obtain accurate topographic parameters for each T-Logger location.

\section{Methods}

Here we provide an overview of the seasonal and spatial variability of air and surface temperature for the three years at all locations investigated. We use these datasets of air and surface temperature to investigate three aspects.

First, we consider the elevation control over air temperature. For this we conduct two main types of analysis. We investigate the relationship between the air temperature measurements over Lirung and the ELR determined for the main valley of the Upper Langtang catchment (Heynen and others, 2016), by calculating the temperature anomaly from this valley ELR. Debris-covered glacier surfaces are assumed to be warmer than the surrounding terrain, because debris, being drier, warms more rapidly than offglacier terrain. This effect should also be felt by the air layer above the debris, resulting in higher average temperatures over the glacier. The ELR is used to extrapolate air

Table 1. Definition of measurement periods and seasons in this study

\begin{tabular}{|c|c|c|c|c|c|}
\hline Year & Time period T-Loggers & $\begin{array}{c}\text { Time period Kyanjing } \\
\text { AWS }\end{array}$ & Pre-monsoon & Monsoon & Post-monsoon \\
\hline T-Logger 2012 & 5 Sep-29 Oct & 1 May-8 Dec & 1 Mar-14 Jun & 15 Jun-19 Sep & 20 Sep-31 Dec \\
\hline T-Logger 2013 & 8 May-31 Dec & 1 Jan-1 Dec & 1 Mar-14 Jun & 15 Jun-19 Sep & 20 Sep-31 Dec \\
\hline T-Logger 2014 & 4 May-25 Oct & 1 Jan-9 Oct & 1 Mar-14 Jun & 15 Jun-19 Sep & 20 Sep-31 Dec \\
\hline
\end{tabular}



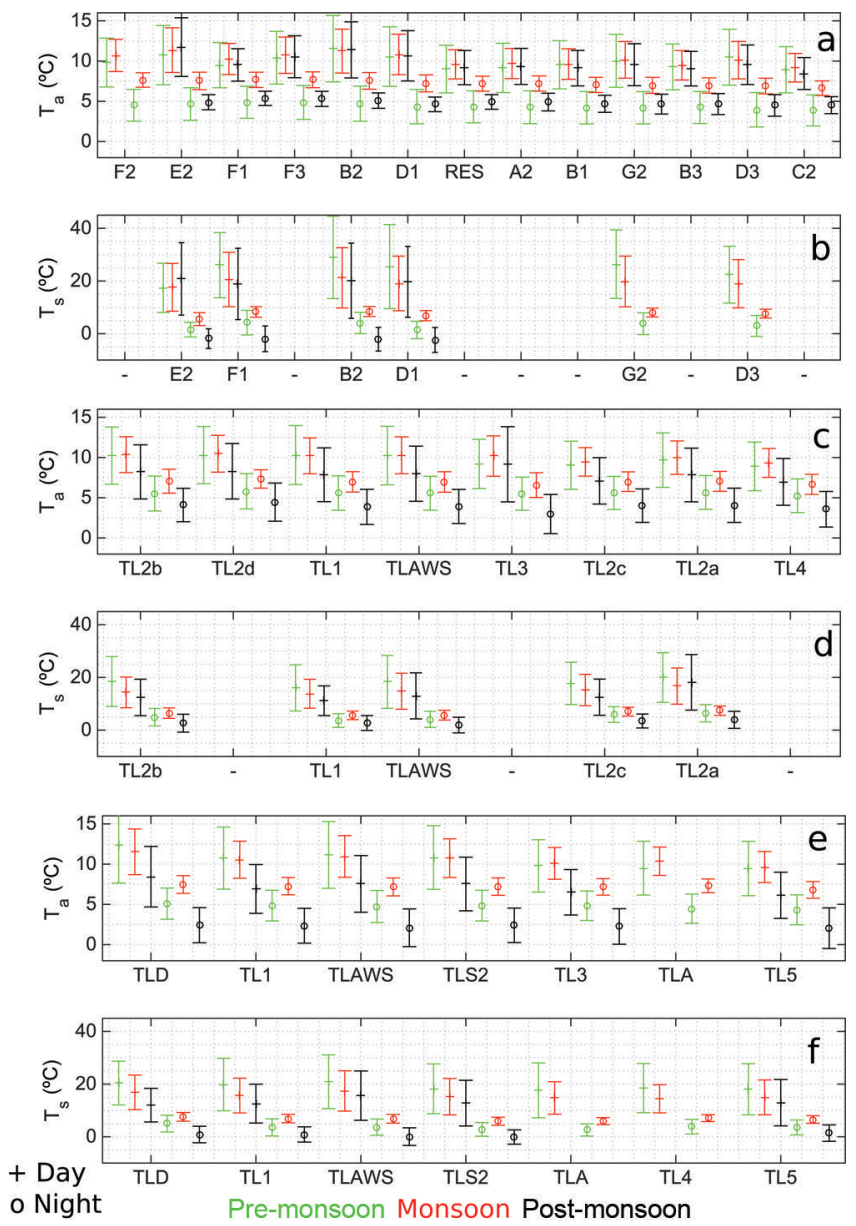

Fig. 4. Mean and standard deviation (indicated by bars) at each T-Logger, separately for daytime and night-time, in 2012 (a, b), 2013 (c, d) and 2014 (e, f). (a, c, e) Air temperature; (b, d, f) surface temperature. The elevation of the T-Loggers increases from left to right.

temperature from the AWS located in the main valley near the village of Kyanjing (Fig. 1). We use mean daily air temperature data from Kyanjing AWS and the ELR derived for all years and separately for each season and compare this extrapolated temperature to the on-glacier measurements. Because there are too few data at Kyanjing AWS in post-monsoon 2014, temperature could not be extrapolated for this season. We then try to identify a glacier $L R$, considering all the on-glacier observations vs elevation. We do this only for the 2012 dataset, as in 2013 and 2014 the elevation range was too small to distinguish a real signal from measurement errors.

Second, we examine whether surface characteristics and topographic attributes can explain the observed variability and provide alternatives to deriving air temperature fields. For this, we calculate the slope, aspect, curvature and skyview factors for every T-Logger location from the highresolution UAV DEM, and use them to interpret both the air temperature anomaly and surface temperature observations.

Third, we conclude by investigating the relationship between air and surface temperature in time and space, building on the regression approach suggested by Foster and others (2012). For this, we fit both linear and piecewise linear regressions to the relationships obtained and analyse which of the two approaches is superior in cross-validation.

\section{TEMPERATURE DATA OVER THE GLACIER SURFACE}

Figure 4 shows the mean and standard deviation of air and surface temperature at each T-Logger location for the three seasons. Surface temperature is generally higher than air temperature during the day, and lower at night-time, at all locations and in all seasons, because of the debris conductive capacity.

The surface temperature has a stronger daily variability than air temperature, especially in 2012, possibly because the surface sensors were not shielded in that year.

In all three years the daytime air temperature in monsoon and pre-monsoon is similar, with mean values ranging between $9^{\circ} \mathrm{C}$ and $12.4^{\circ} \mathrm{C}$. The same is true for post-monsoon in 2012, while in 2013 and 2014 temperatures in postmonsoon dropped markedly. This is probably due to Cyclone Phaelin which struck Langtang from 13 to 15 October 2013 and to Cyclone Hudhud which hit the valley at the same time in 2014. Both events resulted in a marked drop in temperature and high rates of precipitation (Shea and others, 2015).

At night-time, air and surface temperatures are considerably higher in the monsoon than in the two other seasons due to the buffering effect of clouds, which prevent the night-time radiative cooling typical of clear-sky conditions. During the day, the near-continuous cloud cover typical of the monsoon leads to lower temperatures than in the dry seasons as less shortwave radiation reaches the surface. In general, overcast conditions reduce the variability of air temperatures, as suggested by the low standard deviations in the monsoon (Fig. 4a, c and e).

Surface temperatures were unusually high and standard deviations large in 2012, partly because the surface temperature sensors were not covered in foil. In 2013 and 2014, surface temperatures were highest in pre-monsoon, lower in monsoon and lowest in post-monsoon. This is explained by the radiative fluxes at the debris surface. In pre-monsoon the Sun is at a relatively high angle, days are mostly clear and solar radiation warms the debris. In monsoon, the cloud cover prevents direct solar radiation from reaching the surface for most of the day, hence the lower temperature of the surface. In post-monsoon, the inclination of the Sun is at its lowest and many locations were additionally shaded by the local topography.

\section{RESULTS}

Here we report the main results of the three analyses described above. First, we report results of the elevation control over air temperature for the deviations from the valley ELR and for the glacier LR. Second, we discuss whether surface characteristics and topographic attributes can explain the observed variability and provide alternatives to deriving air temperature fields. Third, we show the results of the relationship between air and surface temperature in time and space.

\section{Elevation as a control on air temperature}

\section{Deviation from the valley lapse rate}

Air temperature over the lower tongue of Lirung Glacier is consistently higher than predicted by the valley ELR, more so during the day than at night-time and more strongly in pre-monsoon and post-monsoon (Fig. 5). The much higher temperature anomaly during daytime is due to the much stronger influence of debris heating during the day than the 

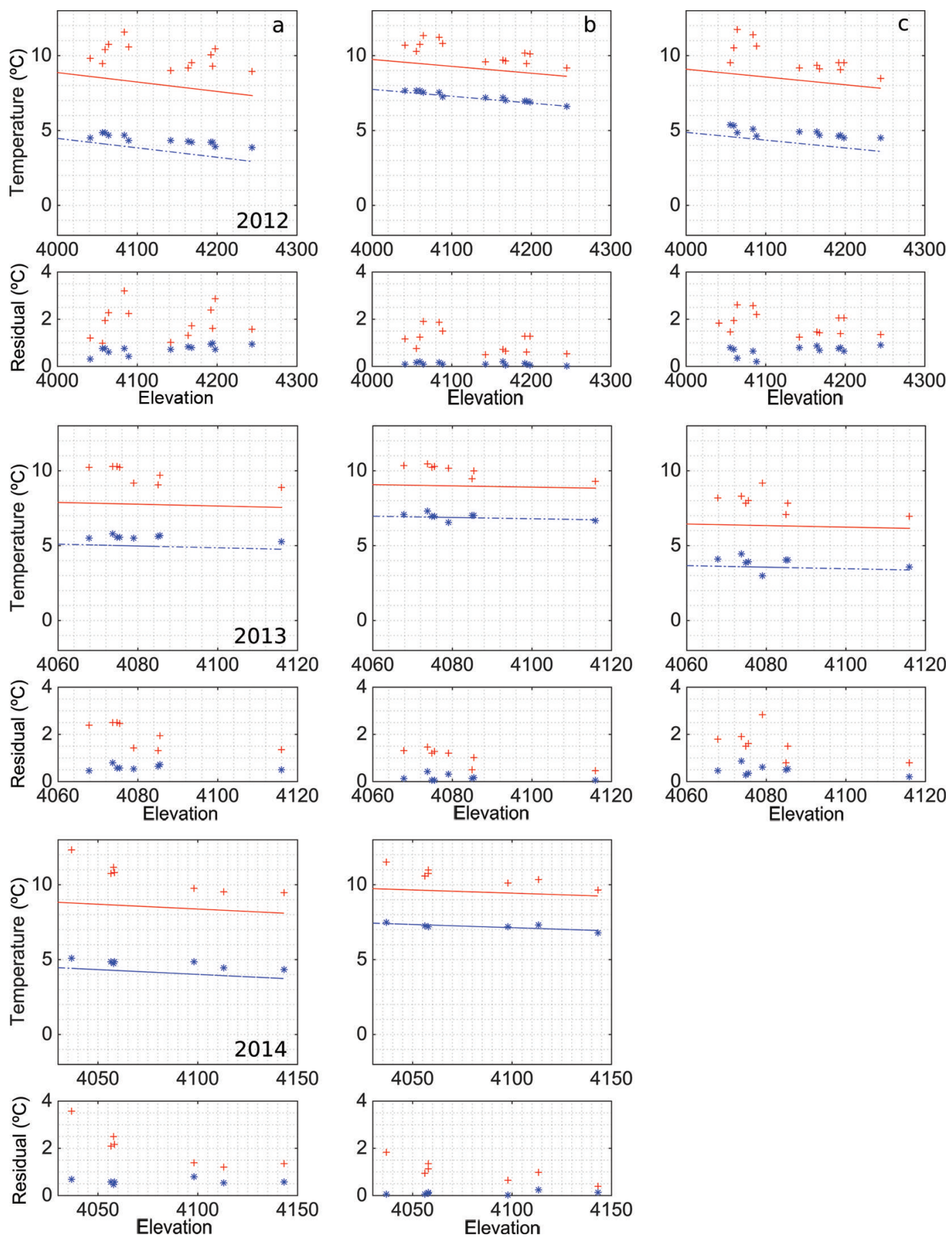

Fig. 5. Mean air temperatures measured at the T-Loggers in the daytime (red) and at night-time (blue) in all three seasons (a-c) and from 2012 to 2014 (top to bottom). The lines show the temperatures determined with the ELR from the off-glacier AWS Kyanjing. The plots at the bottom show absolute deviation of each value from the ELR.

night (Fig. 4). This effect is more or less pronounced depending on the sensor location (see next section). Variability and residuals are larger during the dry seasons, when there is less cloud cover. ELR underestimates daytime air temperature by $1.9-2{ }^{\circ} \mathrm{C}(19-20 \%)$ during pre-monsoon, by only $1-1.1^{\circ} \mathrm{C}(10 \%)$ in monsoon and by $1.6-1.8^{\circ} \mathrm{C}$ $(18-20 \%)$ in post-monsoon.

The ELR provides more accurate results at night-time, when the effect of the debris heating the air layer above plays a much smaller role. However, the residuals are consistently higher during the dry seasons, which indicates the debris is still warmer well into the night-time hours. Night-time temperature is underestimated by $0.6-0.7^{\circ} \mathrm{C}$
(10-17\%) during pre-monsoon, by only $0.1-0.2^{\circ} \mathrm{C}(2 \%$ in all years) in monsoon and by $0.5-0.7^{\circ} \mathrm{C}(12-14 \%)$ in postmonsoon.

It is also evident that, especially in 2012, the daytime temperature observations are more scattered than at nighttime. In 2012, in particular, they seem to cluster around two main groups of values.

Residuals in all years show a clear dependence on elevation. During the daytime, they tend to decrease with elevation, indicating steeper LRs on-glacier than off-glacier. A possible explanation is the likely thinner debris cover in higher regions (e.g. Kirkbride and Deline, 2013), which aligns with local observations but has not yet been 


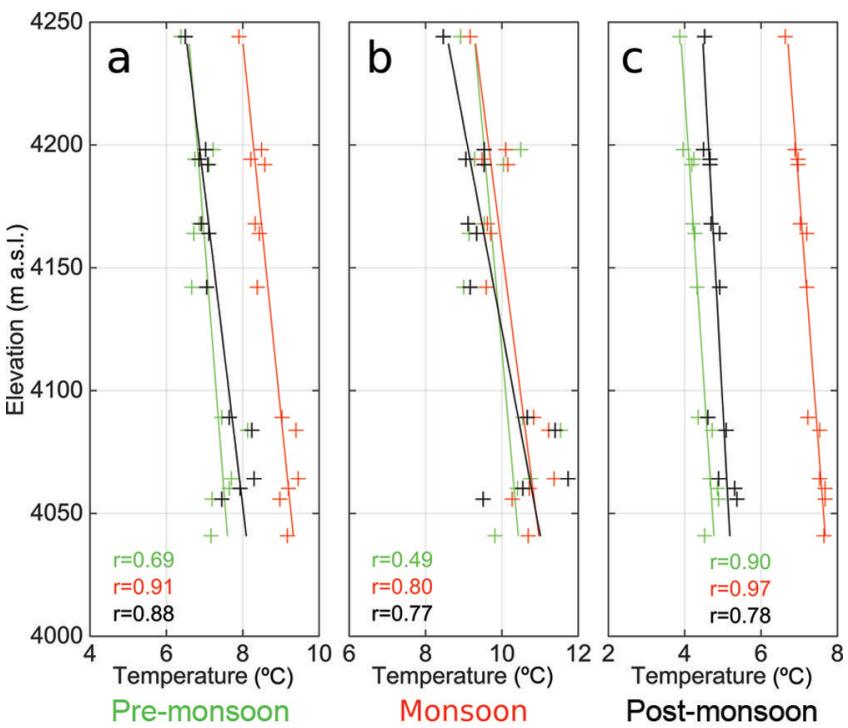

Fig. 6. Elevation vs air temperature for each season (pre-monsoon in green, monsoon in red and post-monsoon in black) in 2012, for (a) the whole day, (b) daytime and (c) night-time. The fitted lines represent the LRs, and the corresponding correlation coefficients are indicated.

confirmed for this glacier on a distributed scale. Additionally, increased shading from the surrounding steep mountain slopes in the upper areas could have a stronger cooling effect at higher elevations.

\section{Glacier lapse rates}

Following the observations above, we calculated a LR from the mean air temperature of each season, and separately for daytime and night-time, for 2012 only. In this year the T-Loggers were distributed over a large portion of the length of the debris-covered tongue and the elevation range between T-Loggers allows a meaningful calculation given the observation errors. In 2012, a LR is evident at night but less so in the daytime (Fig. 6). This is indicated by a strong correlation between air temperature and elevation at nighttime, which weakens in the daytime (Fig. 7). We hypothesize that in the daytime the heating of the debris disrupts a linear relation by coupling air temperature closely to surface
Table 2. Lapse rates between the T-Loggers in $2012\left({ }^{\circ} \mathrm{Cm}^{-1}\right)$. 'Whole day' is the LR for the whole 24 hours, 'daytime' is 08:0019:55 and 'night-time' 20:00-07:55

\begin{tabular}{lccc}
\hline & Pre-monsoon & Monsoon & Post-monsoon \\
\hline Whole day & -0.0050 & -0.0066 & -0.0078 \\
Daytime & -0.0057 & -0.0083 & -0.0120 \\
Night-time & -0.0043 & -0.0049 & -0.0035 \\
\hline
\end{tabular}

temperature and thus overcoming the elevation control. Elevation seems to be restored as the dominant control at night, when surface temperature warming is limited.

The daytime LR is disrupted more during the dry seasons of the pre- and post-monsoon, when the debris heats up more because of higher incoming solar radiation, supporting the hypothesis above. In post-monsoon the LR becomes positive at $\sim$ 07:00 when the Sun rises (Fig. 7). This could be explained by higher locations being hit earlier by direct radiation, resulting in these areas being warmer than lower locations. Brock and others (2010) showed a similar effect on Miage glacier, with a slightly rising LR at approximately this time of day before it decreased sharply.

Glacier LRs show a clear diurnal cycle in all three seasons, with strongly correlated LRs at night-time and weakly correlated LRs in the daytime (Fig. 7), as noted above. Night-time LR is less negative than the generally assumed $\operatorname{ELR}\left(-0.0065^{\circ} \mathrm{Cd}^{-1}\right)$ while daytime LRs are generally more negative than the ELR (Table 2). The diurnal cycle shown in Brock and others (2010), reaching up to $-0.012{ }^{\circ} \mathrm{C} \mathrm{m}^{-1}$ in the daytime, is similar to the diurnal cycle observed in the post-monsoon (Fig. 7).

\section{Topographic controls}

Using the high-resolution DEM, aspect, slope, curvature and sky-view factors were calculated at each T-Logger location (Steiner and others (2015) provide details of the sky-view factor computations). This was done only for the year 2013, for which the T-Loggers were located in close proximity but at sites with different topographic characteristics. In this way we remove as far as possible the effect of elevation and analyse only that of topographic characteristics. Aspect
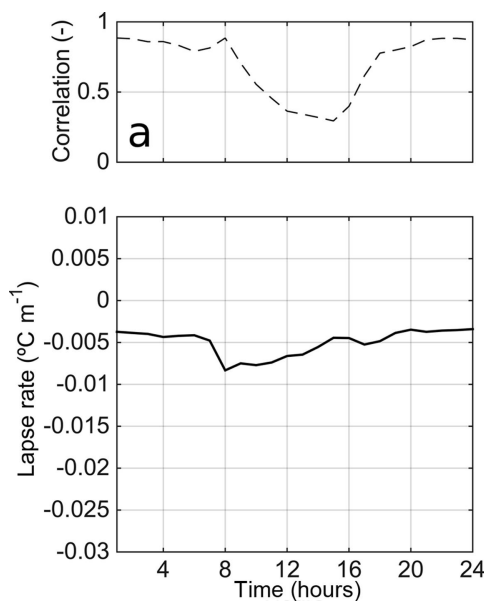
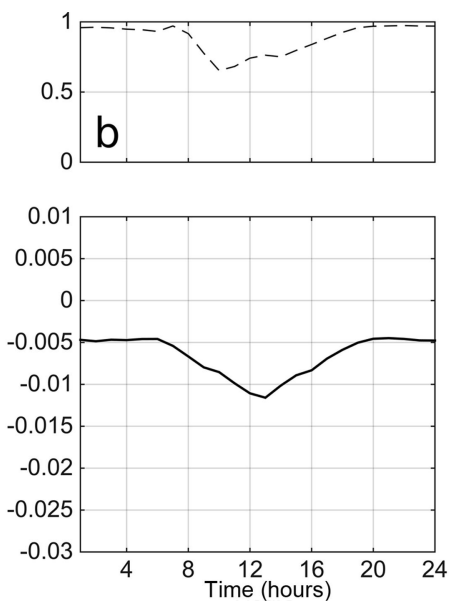
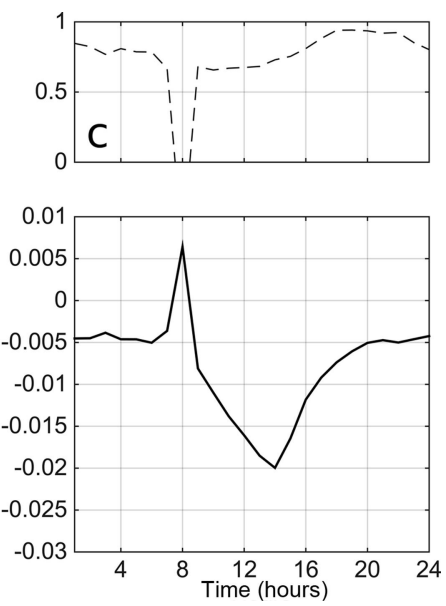

Fig. 7. Mean hourly LRs calculated from all the T-Loggers for pre-monsoon (a), monsoon (b) and post-monsoon (c) in 2012 . The top panels show the correlation coefficient $r$ for all hourly values in the season. 

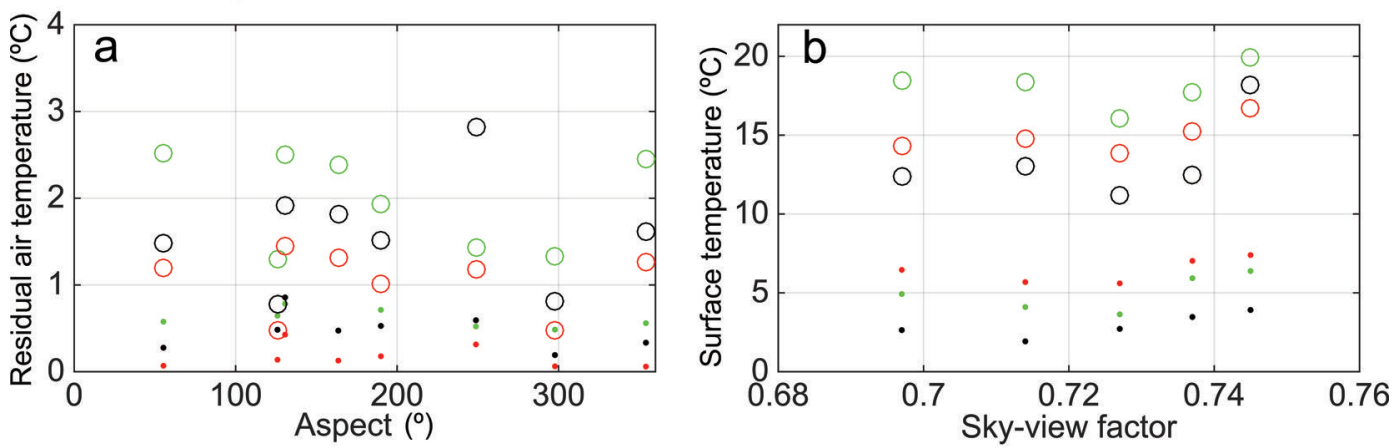

Fig. 8. Air temperature residuals from the valley environmental LR compared to aspect (a) and surface temperature compared to the sky-view factors (b) at each T-Logger, for 2013. $0^{\circ}$ indicates aspect facing north. Not all T-Loggers had working surface sensors.

provides an indication of whether a T-Logger was relatively more or less exposed to the Sun (being more exposed when facing east to south). The sky-view factors describe what fraction of the sky is visible from the sensor. Slope and curvature were also extracted, but since they showed no, or an ambiguous, relation with both air and surface temperature are not discussed further. We use these topographic parameters to seek an explanation for those values that were markedly different from the values that the valley ELR would prescribe.

The deviations of observed from extrapolated air temperature are plotted against aspect in Figure 8a. It can be seen that residuals decrease (and hence measured air temperatures are more similar to those predicted by the valley ELR) consistently for northwest-facing slopes that are shaded from the Sun for most of the time. This seems to reduce the strong effect of solar radiation on the warming debris and air temperature, which thus is more similar to that predicted by the valley ELR. Measured glacier surface temperatures tend to rise with higher sky-view factors (Fig. 8b), again suggesting incoming solar radiation as a main control on variability, as higher sky-view factors indicate that the location received incoming shortwave radiation from a larger portion of the sky. The T-Logger with the highest residual in pre-monsoon and monsoon (TL1) faced east and had the second highest sky-view factor. These effects are also visible, albeit less pronounced, at night-time. This indicates that radiative heating has a lasting effect as longwave radiation from the debris is likely released well into the evening hours.

These first results on the influence of solar radiation through aspect and sky-view factors are encouraging, and seem to point to a clear effect of solar radiation on both air and surface temperature. However, our study is seriously limited by the reduced number of locations that we could equip with both air and surface loggers, and a larger dataset would be needed to explore the full controls of topographic parameters on air and surface temperature and derive robust relationships.

\section{Air and surface temperature relationship}

As shown above, deriving air temperature over the debriscovered tongue of Lirung Glacier with LRs from an offglacier station is questionable in the daytime. Explaining it with topographic controls is still a challenge because of limited data. An alternative approach suggested in the literature (Foster and others, 2012) is to derive it from surface temperature. This approach has great potential because of the availability of surface temperature maps from satellite sensors with a thermal band (e.g. Landsat; Advanced Spaceborne Thermal Emission and Reflection Radiometer (ASTER)). We therefore investigate the relation between air and surface temperature.

Figure 9 shows the diurnal cycles of air and surface temperature at all the T-Loggers in the three years. It should be noted that the sensors at the surface were not covered in foil in 2012, which exposed them to direct incoming solar radiation. They showed higher temperatures in the daytime and cooled off more strongly at night, with an overall larger amplitude than in 2013 and 2014. While this might reflect at least partly real environmental conditions, we decided to exclude this dataset from the following analysis because of the different sensor set-up.

In both 2013 and 2014, surface temperatures rise well above $25^{\circ} \mathrm{C}$ on average in the dry seasons, when cloud cover is rare, and are still $>20^{\circ} \mathrm{C}$ during monsoon (Fig. 9). Surface temperatures exceed air temperatures after sunrise and are lower than air temperature late at night. They vary strongly between the different locations, especially in 2013 when T-Loggers were located on heterogeneous terrain (see especially post-monsoon 2013 in Fig. 9).

We used two approaches to identify a relation between air and surface temperature that is valid over the glacier surface in space and in time. The first uses a linear regression (following Foster and others, 2012) and the second a piece-wise linear regression.

\section{Linear regression}

Following Foster and others (2012), we investigated a linear relationship between air and surface temperature (Fig. 10). The correlation coefficient $r$ for the linear regression is high at all T-Loggers, and on average equal to 0.92, 0.93 and 0.92 in pre-monsoon, monsoon and post-monsoon respectively in 2013 and $0.96,0.94$ and 0.92 in 2014. The relation is, however, not perfectly linear, and there are marked differences between the seasons. The regression is steeper for lower temperatures and shallower above a certain temperature threshold, which seems to depend on time and location. We therefore examined the diurnal variability of the regression lines and calculated their slope and intercept for each hour of the day (considering all temperature data pairs for each hour of the day separately, hence 

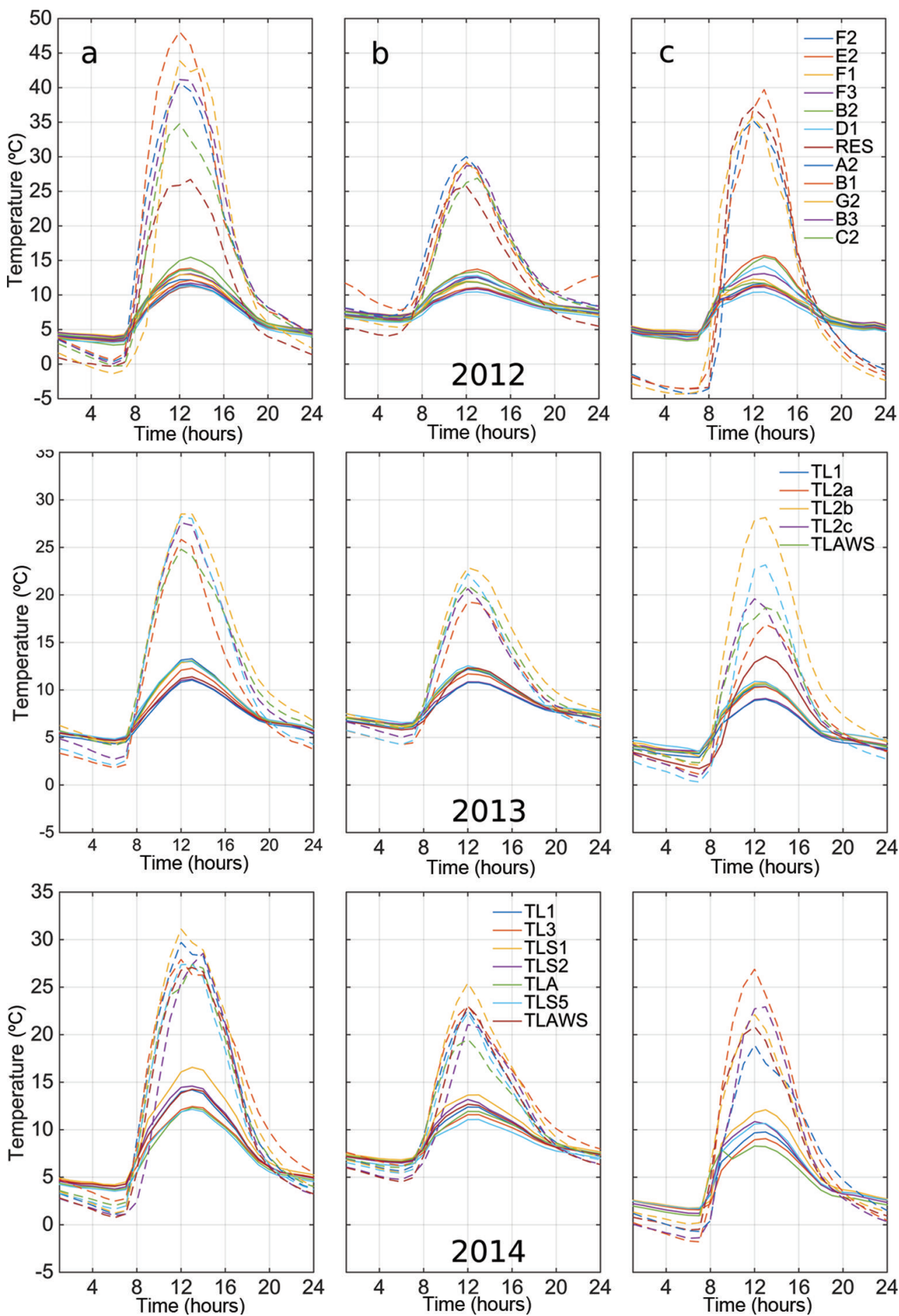

Fig. 9. Diurnal cycles of all T-Loggers in 2012, 2013 and 2014. Solid lines indicate air temperature while dashed lines indicate surface temperature. (a) Pre-monsoon season; (b) monsoon season; and (c) post-monsoon season.

24 regressions per T-Logger and season). Both slope and intercept show a clear diurnal pattern for all T-Loggers, with the exception of the intercept in post-monsoon (Fig. 11). The slope is shallower and the intercept higher in the daytime (Fig. 11), suggesting higher air temperature in the daytime but a stronger decoupling between air and surface temperature. The slope of the linear regression is largely steeper for the dry seasons (green and black in Fig. 11) than for the monsoon season (red in Fig. 11), with the intercept becoming consistently lower. This suggests that during the monsoon, air temperature is coupled less to surface temperature.
In the dry seasons, some of the T-Loggers do not show this pattern clearly, perhaps because the data were scarcer than in the monsoon. This is also confirmed by a relatively higher standard deviation of the intercept between all sensors, $\sigma$, in post-monsoon in the daytime. While clearly more data are required to corroborate our finding, it is encouraging that we obtained the same results for two years (2013 and 2014) for which the sensors were placed at different locations over the debris-covered surface. This suggests that the relationships are robust in time. The small standard deviation $\sigma$ between the different T-Loggers, on the other hand, indicates some spatial robustness (Fig. 11). 

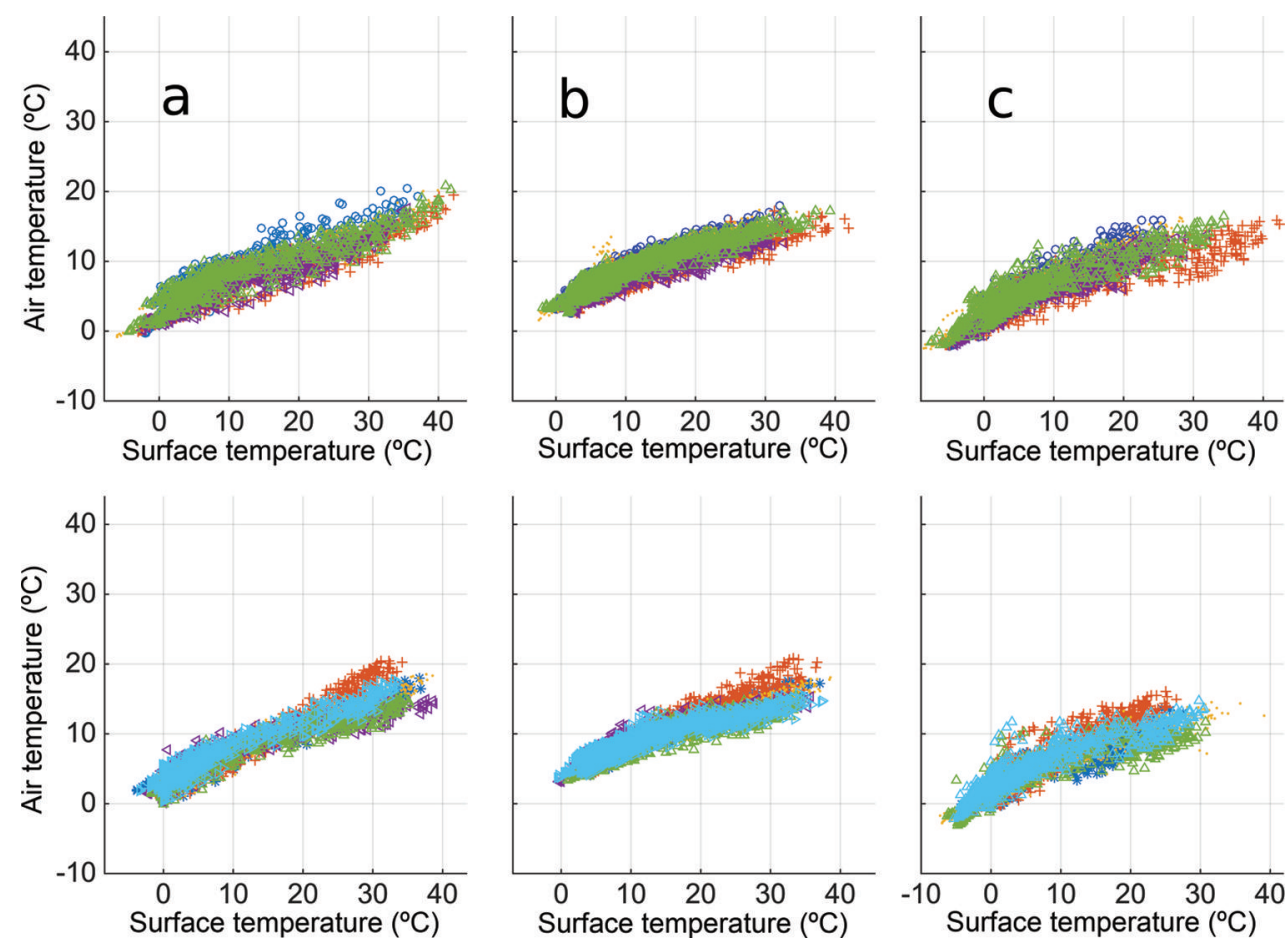

Fig. 10. Hourly air vs surface temperature in the three seasons ((a) pre-monsoon, (b) monsoon, (c) post-monsoon) in 2013 (top) and 2014 (bottom). The different colours are different T-Loggers.
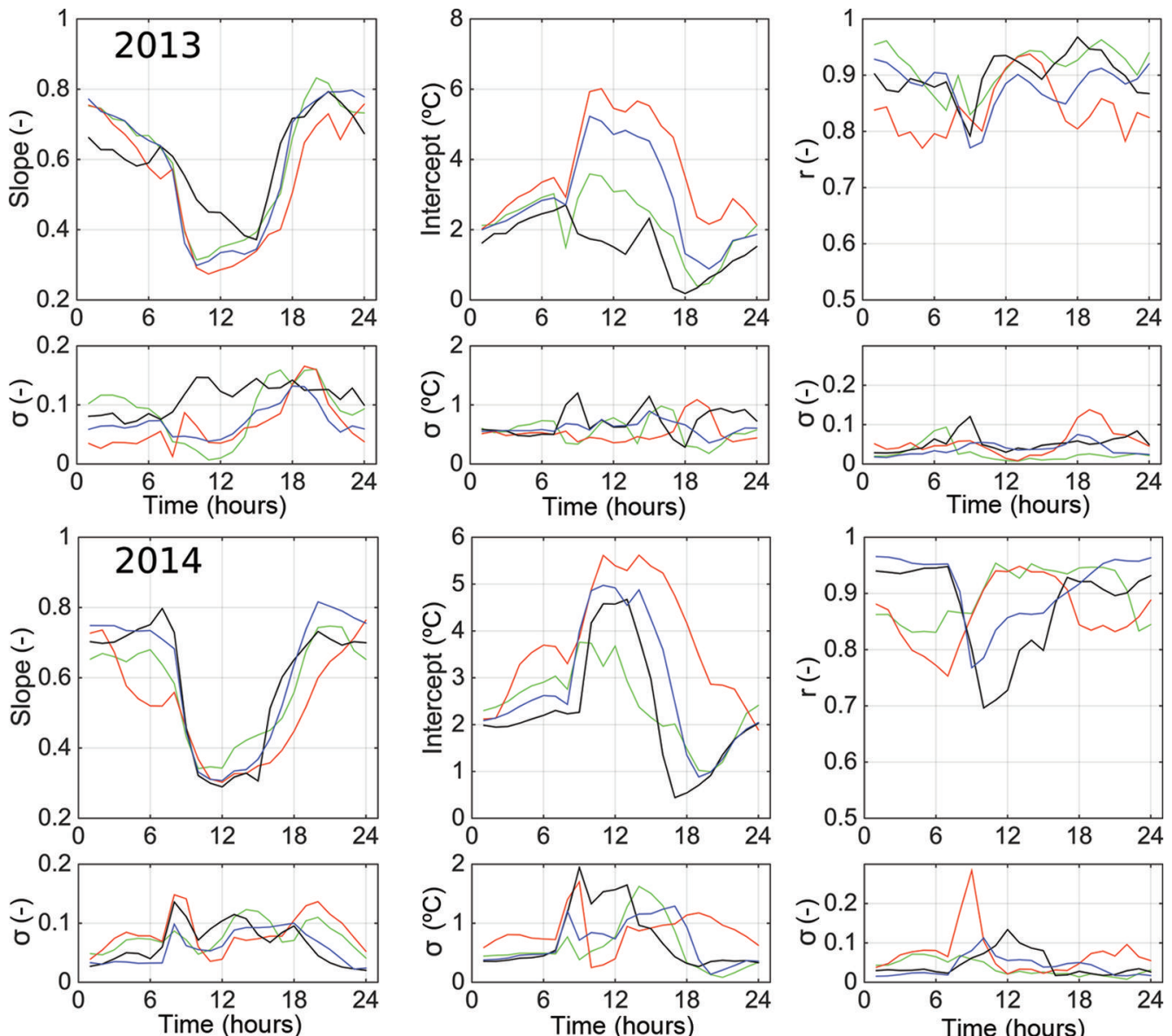

Pre-monsoon

Post-monsoon Total period

Fig. 11. Median slope and intercept for linear regressions at all T-Loggers in 2013 (top) and 2014 (bottom). The seasons are pre-monsoon (green), monsoon (red) and post-monsoon (black), with data for the whole year in blue. Standard deviations $(\sigma)$ are between all locations. The correlation coefficient $r$ in this case is calculated from all measurements in time for each T-Logger. 


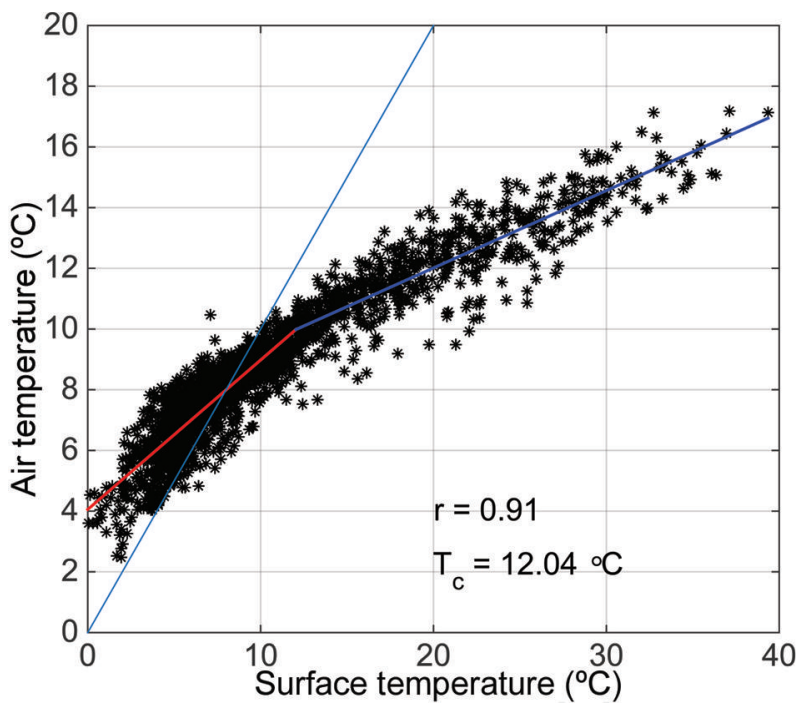

Fig. 12. Example of determination of the piece-wise regressions for T-Logger 5 in pre-monsoon 2013. $T_{\mathrm{C}}$ is the threshold surface temperature where the two regression lines meet.

Piece-wise regression

Since the relation between air and surface temperature seems to exhibit two segments with distinct slopes, we fitted a piece-wise regression at each T-Logger location. We use an algorithm that determines the threshold between the two segments with a least-squares method (Hudson, 1966), and we calculate the threshold $\left(T_{\mathrm{c}}\right)$ and regression parameters, slope and intercept. The method is sketched for one T-Logger in Figure 12. $T_{\mathrm{c}}$ represents the surface temperature at which the correlation coefficient $r$ of both pieces of the regression combined becomes maximal. This approach was applied to all T-Loggers in the three seasons (Fig. 13), and we derived average regression parameters for the three seasons (Table 3).

Apart from one major outlier in 2014 (TLD, at a very warm location) and one in pre-monsoon 2013 (TL1), the
Table 3. Median slopes $\left(a_{1}\right.$ and $\left.a_{2}\right)$ and intercepts $\left(b_{1}\right.$ and $\left.b_{2}\right)$ of the piece-wise approach in all three seasons in 2013 and 2014. The parameter pairs are for the lower and upper segment respectively, which are red and blue in Figure 13. $T_{\mathrm{c}}$ is the threshold temperature $\left({ }^{\circ} \mathrm{C}\right)$. In parentheses are standard deviations $(\sigma)$ between the locations. $r$ is the mean correlation coefficient for the piece-wise regression over all T-Loggers

\begin{tabular}{lcccccc}
\hline Season & $a_{1}$ & $b_{1}$ & $a_{2}$ & $b_{2}$ & $T_{c}$ & $r$ \\
\hline \multirow{2}{*}{ Pre-monsoon } & 0.61 & 2.55 & 0.30 & 4.50 & 6.67 & 0.88 \\
& $(0.08)$ & $(0.59)$ & $(0.02)$ & $(0.49)$ & $(1.09)$ & \\
Monsoon & 0.57 & 3.22 & 0.26 & 5.95 & 9.99 & 0.89 \\
& $(0.05)$ & $(0.61)$ & $(0.05)$ & $(0.55)$ & $(1.65)$ & \\
Post-monsoon & 0.56 & 2.20 & 0.33 & 3.24 & 6.30 & 0.87 \\
& $(0.13)$ & $(0.56)$ & $(0.11)$ & $(1.04)$ & $(3.47)$ & \\
Pre-monsoon & 0.56 & 2.65 & 0.33 & 4.67 & 7.76 & 0.93 \\
& $(0.06)$ & $(0.42)$ & $(0.09)$ & $(1.14)$ & $(4.22)$ & \\
Monsoon & 0.52 & 3.67 & 0.28 & 6.50 & 11.41 & 0.92 \\
& $(0.03)$ & $(0.46)$ & $(0.05)$ & $(0.53)$ & $(2.04)$ & \\
Post-monsoon & 0.59 & 1.84 & 0.29 & 4.00 & 5.83 & 0.89 \\
& $(0.05)$ & $(0.26)$ & $(0.08)$ & $(0.90)$ & $(4.99)$ & \\
\hline
\end{tabular}

segments are fairly similar at all locations; however, the variability increases markedly for the upper segments which describe the relationship between air and surface temperature for the ranges of higher temperatures (Table 3; Fig. 13). The slopes of the upper segment $\left(a_{2}\right)$ are about half as shallow as those of the lower segment $\left(a_{1}\right)$, indicating that below a certain threshold $\left(T_{\mathrm{c}}\right)$, air temperatures rise faster with rising surface temperatures. After that, a certain degree of decoupling occurs, as air-temperature increases cannot follow the increases in surface temperature at the same rate. The slopes of the upper segment are also steeper during the dry seasons, when the air temperature is affected by the incoming direct solar radiation in addition to the heat exchange with the debris below. Also here the relation between air and surface temperature seems to depend more on the location of the sensor, indicated by the higher
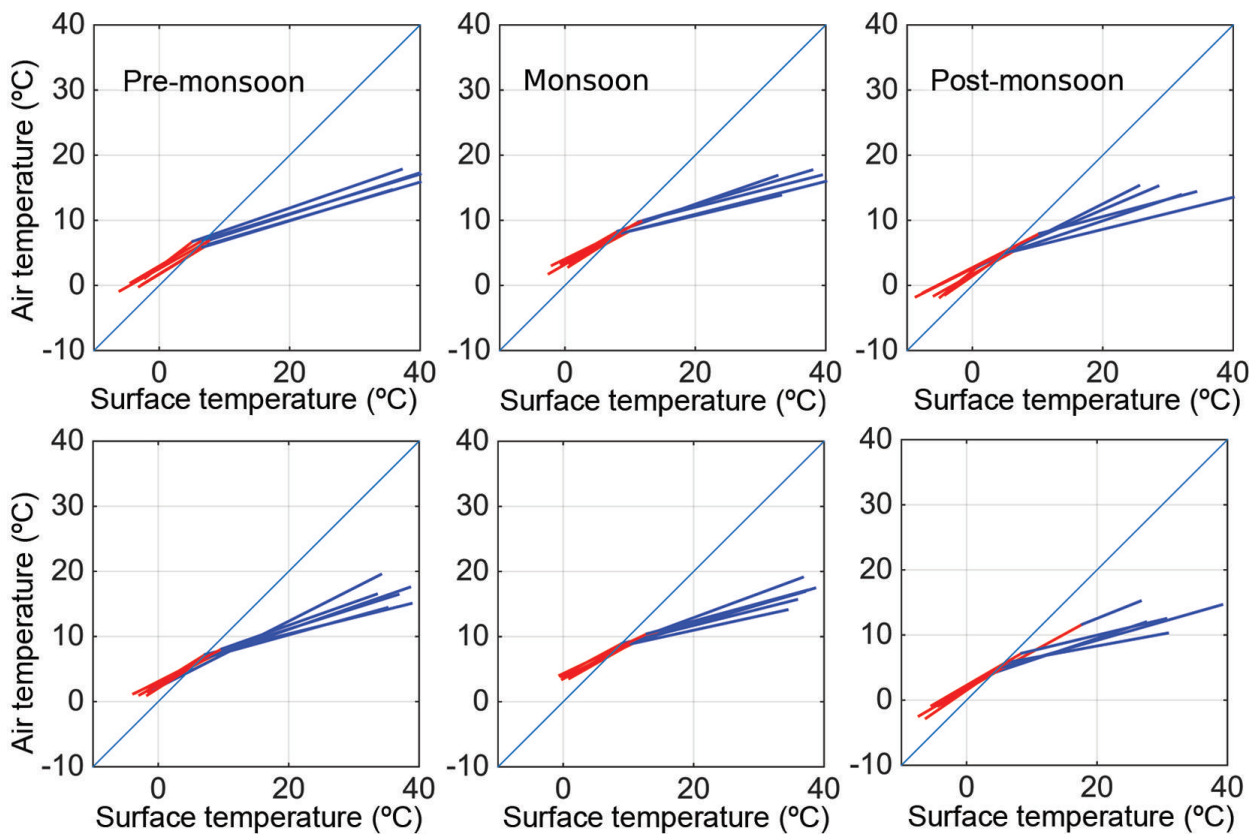

Fig. 13. Piece-wise regressions for all T-Loggers in 2013 (top) and 2014 (bottom). 

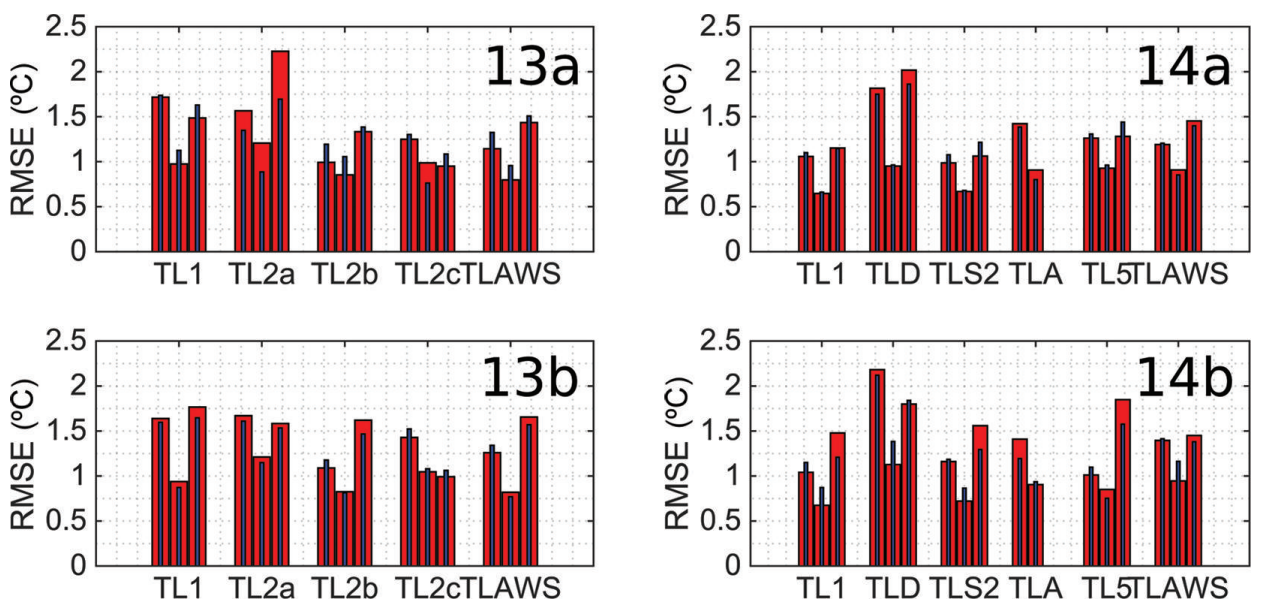

Fig. 14. Root-mean-square error (RMSE) calculated between measured and extrapolated air temperature with the linear regression (red) and the piece-wise regression (blue) in the three seasons at each T-Logger in 2013 and 2014 indicated by the numbers in the panels, 13 and 14, respectively. (a) The fit using the parameter set obtained in the same year; and (b) the fit when using the parameter set from the other year.

variability. Because of one outlier the standard deviation for the threshold $T_{\mathrm{C}}$ is considerably higher in 2014 than 2013.

The threshold temperature $T_{\mathrm{C}}$ might suggest the time when air temperature becomes more decoupled from surface temperature, so we calculated the hours of the day corresponding to $T_{\mathrm{C}}$. Below $T_{\mathrm{C}}$, air temperature rises slowly but consistently at all locations with the heating surface. The decoupling takes place earlier in pre-monsoon (between 07:40 and 08:00) than in monsoon (between 08:30 and 08:40) and post-monsoon (08:30). During the daytime, air temperature is additionally likely affected by wind and incoming solar radiation. This influence, however, is variable depending on the sensor location and exposure. During pre-monsoon this decoupled period lasts nearly 3 hours longer (until 22:00 and 19:30 in 2013 and 2014) than in monsoon (until 19:30 and 17:00) as there is less cloud cover and longer exposure to solar radiation.

\section{Validation}

To evaluate the two approaches above, we calculated a parameter set for each season as the median of the optimal parameter combination at each T-Logger. We then derived air temperature at all T-Logger locations with the median set of parameters and compared the extrapolated air temperature to the measured data. To test the temporal robustness we also applied the parameter sets of one year to the data of the other year. We use the root-mean-square error (RMSE) and the Nash-Sutcliffe efficiency (NSE; Nash and Sutcliffe, 1970) to compare measured and extrapolated air temperature.

A clearly superior performance of one approach over the other is not evident. More evident is the large variability of performance. The average NSE for the linear regression in 2013 is $0.83,0.81$ and 0.79 in pre-monsoon, monsoon and post-monsoon when using the parameters obtained from the same year. At individual T-Loggers the values range from 0.56 to 0.93 , indicating strong variability among locations. The RMSE is $1.33,0.96$ and $1.49^{\circ} \mathrm{C}$. For the piece-wise regression the corresponding NSE are $0.85,0.83$ and 0.81 and RMSE 1.38, 0.96 and $1.46^{\circ} \mathrm{C}$. In 2014 the NSE is considerably higher in pre-monsoon and monsoon $(0.90$ and 0.88 ) but lower in post-monsoon $(0.71)$ and the same for both regression types. The RMSE decreased in all seasons compared to 2013 (Fig. 14).
The lower RMSE during monsoon can be explained by the fact that the extrapolated time series tends to underestimate the high peak values in the daytime and overestimates the low temperatures at night-time. These peak values are less extreme in monsoon, where the nearcontinuous cloud cover reduces incoming solar radiation but also prevents the surface from cooling down to low values during the night, thus maintaining a relatively narrow range of oscillations in air temperature.

Although the median NSE increased when using the piecewise approach in 2013, this increase was not consistent at all T-Loggers. Equally, the RMSE did not indicate a significantly better approach (Fig. 14). The NSE both increases and decreases when the parameter set of the other year is used and so does the RMSE. This suggests that both types of regression are robust in time and can likely be applied to other years with no significant loss in performance.

\section{DISCUSSION AND CONCLUSIONS}

Air temperatures over a debris-covered glacier are subject to feedback from the debris layer that heats up in the daytime and cools down at night. This effect, combined with the rough surface typical of debris-covered tongues, might question the applicability of standard temperature LRs for extrapolating air temperature at the distributed scale (e.g. for energy-balance modelling). We have provided a dataset of air and surface temperature measurements at multiple locations over a debris-covered glacier, which spans the dry and wet seasons during three subsequent years. We used the data to determine how much elevation controls air temperature, to identify alternative topographic controls and to investigate in more detail the relationship between air and surface temperature.

Our data show that strong differences in air and surface temperature exist between the dry and wet seasons that define the climate in the Himalaya. Differentiating between these seasons rather than using relationships valid for the whole year seems to be appropriate. It also seems pertinent to differentiate between daytime and night-time conditions, since high amplitudes in the daily temperature cycle were observed, especially for the surface temperature.

Air temperature over the debris-covered Lirung Glacier tongue is consistently higher than it would be if calculated 
using LRs from observations in the valley. Using a LR determined for the main upper Langtang valley underestimates air temperatures over the glacier consistently during all seasons and during both daytime and night-time. The residuals between lapsed and measured temperatures are especially large in the daytime during the pre-monsoon, amounting to up to $20 \%$ of measured air temperature. At the same time the residuals are also most variable during this period. During monsoon, air temperature is underestimated by $10 \%$ in the daytime and only $2 \%$ at night-time. This suggests that glacio-hydrological models of high-elevation catchments containing debris-covered glaciers need to account separately for extrapolation of air temperature onand off-glacier. While off-glacier temperatures can be extrapolated using LRs determined off-glacier (Immerzeel and others, 2014b; Heynen and others, 2016), the warming over debris-covered glaciers needs to be taken into account. A possible way to do this is to consider an average offset, which seems to be stable over the years investigated but changes seasonally. However, there is still a strong control of elevation over air temperature variability over Lirung, especially at night. During night-time, glacier LRs have a strong correlation, suggesting that they could be used to extrapolate air temperature from on-glacier stations, when available. In the daytime, however, other methods might be needed.

One such method is to derive air temperature from surface temperature, as surface temperature data are often available from remotely sensed data products. Our analysis showed that the linear relationship between air and surface temperature suggested by Foster and others (2012) is suitable. The regressions have a $r$ of $0.92-0.96$ (depending on the season), so it seems generally viable to use surface temperature to determine air temperature with some margin of error (between approximately 0.5 and $2{ }^{\circ} \mathrm{C}$ ). Importantly, the relation seems to be robust across sites (Fig. 11). However, it has a strong diurnal variability and we suggest that different regression parameters should be used for each hour of the day. The slope and intercept vary strongly between day and night, with a slope twice as shallow in the daytime as at night, indicating that air temperature rises much more slowly in the daytime than does surface temperature. This difference between daytime and nighttime suggests that at a certain threshold a decoupling between the temperature of the two media takes place. We have therefore tested as an alternative a piece-wise regression, which differentiates between the warm and cold segments of the temperature cycle. This approach seems to be very robust in space for cold conditions but is less so for warm conditions, where the slope of the regression segment is more variable between different locations. Air temperature also rises more quickly during the dry seasons, when it is not only forced by the debris below but also by more direct solar radiation.

Finally, we have used topographic controls to explain some of the variability that cannot be explained with elevation. Air temperature is especially dependent on the exposition of the debris surface, as this probably determines its exposure to incoming solar radiation. Surface temperatures show a stronger relation to sky-view factors for the same reason. None of these relationships, however, is conclusive since too few data are available, and we suggest that more extensive experiments be conducted to determine a relationship of topography with either air or surface temperature.

\section{ACKNOWLEDGEMENTS}

We thank L. Petersen for organizing the first and second field campaigns in Lirung, and M. Heynen and P. Buri for organizing the third campaign. L. Peterson and S. Wicki contributed some preliminary analysis of the data. P. Hill and I. Rico helped with data collection in the field. We thank T. Rai and his team for assistance in the field, and the International Centre for Integrated Mountain Development (ICIMOD), and J. Shea in particular, for logistics support in Kathmandu. J. Helbing had the original idea of using a T-Logger with this design, which we gratefully acknowledge. This study was funded by the Swiss National Science Foundation (SNF) project UNCOMUN (Understanding Contrasts in High Mountain Hydrology in Asia) and by the US Agency for International Development (USAID) High Mountain Glacier Watershed Program Climber-Scientist (grant No. CCRDCS0010). We are grateful to two anonymous reviewers and Scientific Editor K. Fujita for valuable comments on an early version of this paper.

\section{REFERENCES}

Ayala A, Pellicciotti F and Shea J (2015) A model of air temperature over melting glaciers: common patterns revealed by observations on three alpine glaciers. J. Geophys. Res. Atmos, 120, 3139-3157 (doi: 10.1002/2015JD023137)

Benn DI and 9 others (2012) Response of debris-covered glaciers in the Mount Everest region to recent warming, and implications for outburst flood hazards. Earth-Sci. Rev., 114(1-2), 156-174 (doi: 10.1016/j.earscirev.2012.03.008)

Bolch T and 11 others (2012) The state and fate of Himalayan glaciers. Science, 336(6079), 310-314 (doi: 10.1126/ science.1215828)

Brock BW, Mihalcea C, Kirkbride MP, Diolaiuti G, Cutler MEJ and Smiraglia C (2010) Meteorology and surface energy fluxes in the 2005-2007 ablation seasons at the Miage debris-covered glacier, Mont Blanc Massif, Italian Alps. J. Geophys. Res., 115(D9), D09106 (doi: 10.1029/2009JD013224)

Foster L, Brock B, Cutler M and Diotri F (2012) A physically based method for estimating supraglacial debris thickness from thermal band remote-sensing data. J. Glaciol., 58(210), 677-691 (doi: 10.3189/2012JoG11J194)

Fujita K and Sakai A (2000) Air temperature environment on the debris-covered area of Lirung Glacier, Langtang Valley, Nepal Himalayas. IAHS Publ. 264 (Workshop at Seattle 2000 - DebrisCovered Glaciers), 83-88

Fujita K and Sakai A (2014) Modelling runoff from a Himalayan debris-covered glacier. Hydrol. Earth Syst. Sci., 18, 2679-2694 (doi: 10.5194/hess-18-2679-2014)

Fyffe CL and 6 others (2014) A distributed energy-balance melt model of an alpine debris-covered glacier. J. Glaciol., $60(221)$, 587-602

Greuell W and Böhm R (1998) $2 \mathrm{~m}$ temperatures along melting mid-latitude glaciers, and implications for the sensitivity of the mass balance to variations in temperature. J. Glaciol., 44(146), 9-20

Heynen M, Miles E, Ragettli S, Buri P, Immerzeel W and Pellicciotti F (2016) Air temperature variability in a high-elevation Himalayan catchment. Ann. Glaciol., 57(71) (doi: 10.3189/ 2016AoG71A076)

Hudson D (1966) Fitting segmented curves whose join points have to be estimated. J. Am. Stat. Assoc., 61(316), 1097-1129

Immerzeel WW and 6 others (2014a) High-resolution monitoring of Himalayan glacier dynamics using unmanned aerial vehicles. Remote Sens. Environ., 150, 93-103

Immerzeel WW, Petersen L, Ragettli S and Pellicciotti F (2014b) The importance of observed gradients of air temperature and 
precipitation for modeling runoff from a glacierized watershed in the Nepalese Himalayas. Water Resour. Res., 50(3), 2212-2226 (doi: 10.1002/2013WR014506)

Kirkbride M and Deline P (2013) The formation of supraglacial debris covers by primary dispersal from transverse englacial debris bands. Earth Surf. Process. Landf., 38(15), 1779-1792 (doi: 10.1002/esp.3416)

Mihalcea C, Mayer C, Diolaiuti G, Lambrecht A, Smiraglia C and Tartari G (2006) Ice ablation and meteorological conditions on the debris-covered area of Baltoro glacier, Karakoram, Pakistan. Ann. Glaciol., 43, 292-300

Minder JR, Mote P and Lundquist J (2010) Surface temperature lapse rates over complex terrain: lessons from the cascade mountains. J. Geophys. Res., 115, D14122 (doi: 10.1029/ 2009JD013493)

Nash J and Sutcliffe J (1970) River flow forecasting through conceptual models part I - A discussion of principles. J. Hydrol., 10(3), 282-290

Pellicciotti F, Stephan C, Miles ES, Immerzeel WW and Bolch T (2015) Mass balance changes of the debris-covered glaciers in the Langtang Himal in Nepal between 1974 and 1999. J. Glaciol., 61(226), 373-386 (doi: 10.3189/2015JoG13J237)

Petersen L and Pellicciotti F (2011) Spatial and temporal variability of air temperature on a melting glacier: atmospheric controls, extrapolation methods and their effect on melt modeling, Juncal Norte Glacier, Chile. J. Geophys. Res., 116(D23), D23109 (doi: 10.1029/2011JD015842)

Petersen L, Pellicciotti F, Juszak I, Carenzo M and Brock B (2013) Suitability of a constant air temperature lapse rate over an alpine glacier: testing the Greuell and Böhm model as an alternative. Ann. Glaciol., 54(63), 120-130 (doi: 10.3189/ 2013AoG63A477)
Ragettli S and 9 others (2015) Unraveling the hydrology of a Himalayan watershed through integration of high resolution insitu data and remote sensing with an advanced simulation model. Adv. Water Res., 78, 94-111

Reid TD, Carenzo M, Pellicciotti F and Brock BW (2012) Including debris cover effects in a distributed model of glacier ablation. J. Geophys. Res.: Atmos., 117(D18) (doi: 10.1029/ 2012JD017795)

Scherler D, Bookhagen B and Strecker MR (2011) Spatially variable response of Himalayan glaciers to climate change affected by debris cover. Nature Geosci., 4(3), 156-159 (doi: 10.1038/ ngeo1068)

Shaw T, Brock B, Fyffe C, Pellicciotti F, Rutter N and Diotri F (2016) Air temperature distribution and energy-balance modelling of a debris-covered glacier. J. Glaciol., 62

Shea JM and Moore RD (2010) Prediction of spatially distributed regional-scale fields of air temperature and vapor pressure over mountain glaciers. J. Geophys. Res., 115(D23), D23107 (doi: 10.1029/2010JD014351)

Shea J, Wagnon P, Immerzeel W, Biron R, Brun F and Pellicciotti F (2015) A comparative high-altitude meteorological analysis from three catchments in the Nepalese Himalaya. Int. J. Water Res. Dev., 31, 174-200

Shiraiwa T and Yamada T (1991) Glacier inventory of the Langtang Valley, Nepal Himalayas. Low Temp. Sci., 50, 47-72

Steiner JF, Pellicciotti F, Buri P, Miles E, Immerzeel WW and Reid T (2015) Modeling ice-cliff backwasting on a debris-covered glacier in the Nepalese Himalaya. J. Glaciol., 61(229), 889-907 (doi: 10.3189/2015JoG14J194)

Zhang Y, Fujita K, Liu S and Liu Q (2011) Distribution of debris thickness and its effect on ice melt at Hailuogou glacier, southeastern Tibetan Plateau, using in situ surveys and ASTER imagery. J. Glaciol., 57(206), 1147-1157 